\title{
LA VID Y EL VINO EN JUMILLA. CRISIS Y CONFIGURACIÓN DE UN COMPLEJO VITIVINÍCOLA INNOVADOR
}

\author{
Gabino Ponce Herrero y Antonio Ramos Hidalgo \\ Facultad de Filosofía y Letras, Universidad de Alicante
}

\section{RESUMEN}

Del análisis de la evolución reciente de complejo vitivinícola desarrollado en Jumilla después de 1976, se observa una profunda transformación desde una cuenca productora de vino de mesa de alta graduación a precios bajos, hasta un sistema productivo local innovador e integrado horizontal y verticalmente. La gran reducción de la superficie de cultivo y la merma en los vinos a granel y de mesa, se ha compensado por el desarrollo de estrategias de calidad y competitividad internas en las empresas y, también, gracias a la construcción de una organización territorial activa, que potencia redes de cooperación y colaboración entre agricultores, empresas e instituciones. El cambio apunta hacia las esencias de un territorio inteligente, bien que con algunas aristas.

Palabras clave: viticultura, bodegas, calidad, marcas, territorio

\section{SUMMARY}

Vines and wines in Jumilla. Crisis and configuration of an innovative wine-producing area

Analysis of how the wine-production sector has evolved in Jumilla since 1976 reveals a profound transformation from a region producing high-grade low-cost table wine to an innovative local production system with both horizontal and vertical integration. The major drop in the amount of land used for vine production and the lower amounts of bulk and table-quality wine produced have been compensated for by the development of internal quality and competitiveness strategies in the area's wine-producing businesses, and by the establishment of an active land organisation that helps boost co-operation networks and collaboration between farmers, businesses and institutions. The change suggests the makings of a region with intelligent land use, albeit with a few rough edges.

Keywords: wine production, wineries, quality, brands, land 


\section{INTRODUCCIÓN}

El viñedo, cultivo atávico en la Región de Murcia, desde las últimas décadas del siglo pasado mantiene una clara tendencia descendente en cuanto a superficie ocupada, en relación inversa a la constante cualificación de las técnicas de cultivo. Las 30'5 mil Ha plantadas en el año 1904, se duplicaron en la primera mitad de ese siglo, de acuerdo con la adaptabilidad ecológica del cultivo en los secanos del interior murciano y merced al paulatino aumento de una demanda poco cualificada, de un producto esencial en la dieta doméstica. Sin embargo, las 66'4 mil Ha cultivadas en 1975, se han visto mermadas en la presente centuria prácticamente a la mitad: $37 \mathrm{mil} \mathrm{Ha}$ en 2010. Tal descenso obedece a la apertura de los mercados, la internacionalización de la competencia y, también, a un sensible descenso en el consumo medio de los españoles, principal mercado de la producción murciana de vinos.

El estancamiento de los precios de comercialización de la uva para vinificación, al menos desde principios del siglo actual, o su ritmo de crecimiento por debajo del incremento de los costes de producción, han llevado a la viticultura a una situación extremadamente difícil en sus balances de sostenibilidad económica, saldada con frecuencia por el abandono o el levantamiento de grandes extensiones, auspiciadas hasta hace unos años por la Unión Europea.

Sorprende esa circunstancia precisamente al compararla con la alta innovación desarrollada por la vinicultura. Las bodegas locales, creadas por los viticultores para dar salida a la gran producción de vinos, se han erigido en el epicentro del moderno sistema productivo desarrollado en torno a la vid. Sobre la producción del vino -producto final-gravita todo un sistema económico que supedita a los viticultores, relegados a la función de productores de bienes intermedios para el uso industrial: la uva, sujeta a un largo proceso de depreciación (Alonso, Aparicio y Sánchez, 2002).

También las bodegas han ido asumiendo el proceso de la distribución comercial, paulatinamente y conforme con su capacidad de gestión, al ser entes muy vinculados con la demanda. De productores en manos de comerciantes ajenos a las bodegas, se está pasando a nuevas estructuras que asocian producción y comercialización, con notable éxito. Así, por un lado, la inserción en las dinámicas del mercado con marcas propias ha permitido a las bodegas estar muy pendientes de las modas, gustos y flujos del consumo en las escalas estatal e internacional. Por otro lado, precisamente para complementar la oferta de marca, las bodegas más innovadoras han adquirido otras marcas, con vinos de otras regiones, que comercializan bajo la misma estructura empresarial que, de ese modo, alcanza difusión transregional y, también, transnacional.

Esa podría ser la cuestión, ya destacada por Unwin (2001) como motor del cambio innovador en los sistemas productivos que giran en torno al vino: el 
mercado y sus tendencias serían los responsables del constante ajuste de un sistema productivo dinámico, que impulsa la innovación comercial, vinicultora y viticultora, por ese orden y en grado decreciente.

Que sea la distribución comercial el principal agente de los procesos de cambio no es raro. De hecho ya se dio durante la segunda mitad del siglo XIX, con motivo de las plagas sucesivas de mildiu y filoxera que afectaron a los viñedos franceses y propulsaron la plantación de vides en Murcia y otras regiones del Mediterráneo español (Piqueras, 1981) ante la gran demanda de vinos para la exportación: en Jumilla, entre 1880 y 1905 la superficie cultivada se multiplicó por cinco (Morales, 1976).

Interesa conocer ahora si el sistema productivo local desarrollado en Jumilla alrededor del cultivo, elaboración y comercialización de vinos se hallan en un proceso de retroceso por caída de la demanda, o en una fase de ajuste, por la innovación, hacia unas estructuras más productivas y competitivas. Se retoma el análisis en el punto en que lo dejó Morales Gil (1976: 66) cuando señalaba: ...el desarrollo del cultivo va a ser abrumador, hasta desembocar en la actualidad -1975- en que éste ha adquirido tal importancia que hace pensar en que el área de Denominación de Origen Jumilla llegará a convertirse en monocultivo de la vid.

Para el estudio de esta última etapa, los datos obtenidos de los anuarios de producción agrícola del Ministerio de Agricultura, así como los obtenidos directamente de las bodegas de Jumilla y del Consejo Regulador de la Denominación de Origen Jumilla, se interpretarán bajo el prisma de diversos modelos analíticos, empleados ya para comprender la fuerte reestructuración experimentada por los sistemas productivos manufactureros entre los años 1980 y 1990 (Ponce, 2003), con los que el proceso de la vid en Jumilla parece presentar bastantes similitudes.

\section{El MODElo EVOlutivo De HinNeWINKel}

Mediante un modelo evolutivo, para explicar el alto grado de desarrollo alcanzado por la viticultura y la vinicultura de Burdeos, Hinnewinkel (2009) establecía cuatro etapas bien definidas en las que los agentes locales, afectados por las dinámicas del mercado, han evolucionado en sentido favorable o negativo. Sólo a efectos de llegar brevemente a la última etapa, que es la que interesa al objeto de este estudio, se presentan las anteriores.

\section{Un cultivo histórico para el mercado local}

Para Hinnewinkel, los orígenes de un sistema productivo de éxito basado en la elaboración de vinos se fundamentan en la existencia de una larga y secular tradición en la comercialización, a veces por ubicarse la zona junto a un importante 
puerto, otras veces por detentar privilegios reales para esa venta, en un mercado muy controlado. No parece ese el caso de la vid en Jumilla.

Históricamente, la vid ha sido cultivo menor en este municipio y en todo el interior de la Región de Murcia. En Jumilla, en el s. Xvi se documenta como «un pequeño sector de viñas de regadío al pie de la villa» (Palencia, 1963: 166), al tiempo que las Relaciones Topográficas de Felipe II, en 1579, se indicaba que la producción de vino era tan magra que hacía falta importar de pueblos manchegos (Cebrián y Cano, 1992). El Catastro del Marqués de la Ensenada, en 1757, recoge la existencia de 335 Ha. En 1859, el Diccionario de Madóz apuntaba a unas $500 \mathrm{Ha}$, y para 1877 Morales (1976: 53) calcula unas 1.500 Ha. No existen datos individualizados para conocer el crecimiento de la vid en Jumilla a finales de esa etapa dorada de elaboración y exportación, pero del Avance Estadístico sobre cultivo y producción de la vid en España, de 1889, que da una cifra de 21.469 Ha para el partido judicial de Yecla (municipios de Yecla y Jumilla), se puede calcular alrededor de 11.600 Ha para Jumilla. En 1960 la superficie ascendía a 17.714 Ha (Morales, 1976: 69), con un espectacular crecimiento, hasta llegar a las $30.308 \mathrm{Ha}$ que recoge el Catastro vitícola y vinícola de 1978.

Esto es, pese a la existencia documentada del cultivo de la vid en Jumilla desde la Antigüedad (Molina y Molina, 1991), la producción fue siempre muy limitada circunscrita al abasto de la demanda local. Es la fuerte demanda de vinos experimentada en las últimas décadas del siglo XIX por los mercados franceses, la que impulsaría el primer crecimiento significativo de la vid en el municipio, favorecida por la red de comunicaciones del Vinalopó (carretera general y, especialmente, ferrocarril) por donde se daba salida a las grandes producciones hacia el puerto de Alicante (Ponce, 2014), mucho más próximo y mejor comunicado con Jumilla que el de Cartagena.

Morales (1970) ha señalado como buena parte de las tierras desamortizadas entre 1868 y 1875 , bajo el sistema de colonización en aparcería y, sobre todo, en enfiteusis, se destinaron al cultivo de la vid, pero también de cereales y olivo: la cesión temporal del dominio útil en enfiteusis obliga al colono a pagar una renta anual, lo que es más fácil en el caso de los cereales, comercializables desde el primer año, que en el de la vid, que comienza a dar rendimientos a los 3 o 4 años y alcanza su óptimo de producción alrededor de los 20 años de edad, para luego decrecer. La enfiteusis, fórmula medieval de tenencia de la tierra (Gil, 1979), en la segunda mitad del s. xIx y principios del s. xx fue el método esencial de la ampliación de los cultivos de secano por todo el interior de la provincia de Murcia y, con ellos, de la difusión del viñedo por esas comarcas más ajustadas ecológicamente (Piqueras, 2000). 


\section{Diferenciación del producto y ampliación de los mercados}

La segunda etapa se da con la ampliación del circuito comercial de la mano de la diferenciación del producto. Etapa cubierta en los siglos XVII y XVIII en Burdeos (Hinnewinkel, 2007: 7), empezó a desarrollarse también en la D.O. Alicante a partir de la variedad monastrell, con la que se elaboraba el fondillón, vino dulce con alta graduación (parecido a los vinos dulces de Jumilla) que alcanzó gran demanda internacional -en competencia con el xerez y el oporto- y fijó en esa ciudad portuaria un nutrido colectivo de mercaderes italianos, franceses, ingleses y alemanes (Poveda, 2008). Sin embargo, las referencias para los vinos de Murcia en ese momento (sin duda de viñedos acantonados en el Campo de Cartagena, junto al puerto de expedición) son muy vagas (Plasencia, 1994).

La tercera fase se da cuando la zona productora, ya consolidada comercialmente, busca mejorar su posición de mercado mejorando la calidad, elaborando un producto más exclusivo y caro. Se dio en los siglos XVIII y xIX en Burdeos, pero se truncó en el Mediterráneo español precisamente por la gran demanda de vinos de baja calidad y alta graduación demandada por los vinateros franceses, con ocasión de las epidemias de mildiu y filoxera de mediados del s. XIX que asolaron sus viñedos.

En 1834, los decretos reales de liberalización del comercio interior y exterior habilitaron los puertos de Alicante y Cartagena para la exportación de vinos a Francia. Mayor impacto tuvo la inauguración del ferrocarril Madrid-Alicante (1858) y Madrid-Cartagena (1868). Si bien, los vinos de Jumilla salieron particularmente por la compañía VAY (Villena, Alcoy, Yecla) ${ }^{1}$, que inauguraba la estación de Yecla en 1889 y la de Jumilla en 1903. Ese tendido conectaba en Villena con la línea MZA (Madrid, Zaragoza, Alicante) que podía trasladar los vinos del Altiplano Jumilla-Yecla hacia los grandes exportadores alicantinos.

La crisis de la filoxera en los viñedos franceses y la mejora cualitativa de las comunicaciones -ferrocarril y puerto de mar- fueron decisivas para el primer auge de los viñedos de Jumilla, más importante incluso que el alcanzado en otras zonas mejor comunicadas. En 1877 el municipio contaba con unas 3.000 Ha en apreciación de Morales (1976: 53 y 61) y con unas 11.000 en 1889. En ese año, el Partido Judicial de Yecla (Yecla y Jumilla) sumaba un total de 21.469 Ha (20.943 Ha de secano), que suponían el 64,5\% del total de la superficie de vid de la Provincia (33.297 Ha); cuando, por ejemplo, las principales zonas

1. La compañía de ferrocarriles de vía estrecha «Villena, Alcoy, Yecla» funcionó entre 1884 y 1969, conocida popularmente como «el Chicharra». Permitió la pronta salida de los vinos de Yecla hacia el puerto de Alicante, favoreciendo la más temprana expansión de sus viñedos. En 1921 llegó a Jumilla y en 1924 a Cieza, permitiendo la salida hacia los puertos y ciudades de Alicante, Gandía y Valencia. 
vinateras de Alicante, como el Partido Judicial de Villena sumaba 16.972 Ha, o el de Monóvar 12.190 Ha (Dir. Gral. Agri., 1891).

Pero la producción se destinó básicamente hacia vinos a granel, que debían acabar mezclados (coupage) en Francia, para su posterior crianza según los modernos métodos bordeleses de la época, para seguir abasteciendo sus mercados. Pudo ser el momento clave para introducir en España la elaboración de vinos de calidad conforme con las técnicas más avanzadas, pero los comisionistas franceses sólo se dedicaron a preparar los vinos para que pudiesen soportar el transporte a Francia (Oestreicher, 2005). En ese sentido, Pardo (1996: 27) señala cómo los comerciantes franceses introducían en Jumilla nuevas formas de elaboración, acabando con los sistemas tradicionales... «para así complacer a los consumidores».

La fuerte dependencia comercial y tecnológica ocasionó la gran crisis de los viñedos mediterráneos en general y, en particular de Jumilla. La propia sobreproducción llevaba en sí el germen de la crisis. De ese modo, con el fin del tratado comercial con Francia para la exportación de vinos (año 1892), la vid ya se había depreciado considerablemente: en 1886 se pagaban 38 pesetas por $\mathrm{Hl}$ de vino, y en 1891 tan sólo 16 pesetas/Hl (Pardo, 1996: 29).

En opinión de Hinnewinkel, en la tercera fase radica la clave del éxito de un sistema productivo vitivinícola: la búsqueda de la excepcionalidad a partir de un proyecto común de organización social y económica para mantener la calidad de los vinos. La actuación de los agentes comerciales franceses en Jumilla (y en toda la España mediterránea) es prueba clara de esa estrategia de proyecto común. Sin embargo, en España la crisis se llevó por delante todo el conocimiento atesorado, la tradición y la calidad. Los bodegueros de Jumilla, como otros, optaron por la producción masiva, rebajando las calidades: primero como estrategia de ganancia rápida $\mathrm{y}$, a partir de la crisis de la filoxera, como estrategia de supervivencia de la viticultura.

Precisamente, un siglo después, el nuevo Plan Estratégico de la Denominación de Origen Jumilla 2007-2011 apunta en sus recomendaciones hacia la diferenciación, la imagen de marca y el control de los procesos de elaboración y comercialización como principales bazas para relanzar el sistema productivo (Deloitte, 2007).

\section{La democratización de la demanda y el auge de la segunda mitad del s. XX}

Para Hinnewinkel, la cuarta fase (que sitúa en Burdeos en los siglos XVIII y XIX) se caracteriza por la democratización del consumo de vino y el aumento considerable de la demanda, abastecida por vinos de diversas calidades para cada uno de los segmentos del mercado. Tras la crisis de principios de siglo xx, esa etapa se retrasó en Jumilla hasta la segunda mitad de la centuria, enlazando 
con la etapa que Morales (1976: 66) clasifica como «el resurgir del viñedo desde 1950».

Aunque la afección fue importante en el conjunto de la Provincia, no existen referencias de que la filoxera afectara gravemente a los viñedos de Jumilla, circunstancia que Morales (1976: 63) atribuye a las características de los suelos calizos y pedregosos de los glacis sobre los que se difundió el viñedo. Sin embargo, esa afección y la caída de la demanda si tuvo un grave impacto en el conjunto de la superficie cultivada de la Provincia, que pasó desde las 87.210 Ha registradas en el Anuario Estadístico de 1904, a las 44.303 Ha que da el Anuario de 1950 (INE).

En opinión de Morales, sumados ambos aspectos negativos (filoxera y crisis comercial) la pérdida generalizada de interés en ese cultivo se minimizó en Jumilla, que habría pasado desde las $11.000 \mathrm{Ha}$ de 1889 a unas $8.000 \mathrm{Ha}$ en 1935, para recuperar desde esos momentos el cultivo y llegar a las $16.410 \mathrm{Ha}$ en 1950 (INE). Debe tenerse en cuenta la falta de alternativas, en los secanos del interior, representada sólo por los cereales y, sobre todo, la depreciación de los costes laborales, como nueva medida competitiva para mantener el cultivo. En ese sentido, el cuadro que muestra la evolución (base 100) de los salarios medios en España a partir del impacto de la guerra civil, recoge cómo la depreciación de los salarios es siempre inferior al índice de productividad, tanto en la agricultura, como en la industria (bodegas).

Cuadro 1. Impacto de la guerra civil (1936-1939) en los salarios y la productividad de los sectores económicos de España

\begin{tabular}{|c|c|c|c|c|}
\hline & $\begin{array}{c}\text { Índice de salario } \\
\text { agrícola \% }\end{array}$ & $\begin{array}{c}\text { Índice de salario } \\
\text { industrial \% }\end{array}$ & $\begin{array}{c}\text { Índice de } \\
\text { productividad } \\
\text { agrícola \% }\end{array}$ & $\begin{array}{c}\text { Índice de } \\
\text { productividad } \\
\text { industrial \% }\end{array}$ \\
\hline 1935 & 100 & 100 & 100 & 100 \\
\hline 1950 & 56 & 74 & 58 & 108 \\
\hline 1954 & 55 & 90 & 65 & 138 \\
\hline
\end{tabular}

Fuente: Herrero Castro, JL. 1987

Esa etapa se saldaría con un importante proceso de emigración de la mano de obra de Jumilla, que contaba con 20.340 habitantes en 1920 y 20.988 habitantes en 1950. En los secanos de la Región, la modernización y capitalización de la agricultura fue un momento crítico que fomentó una oleada de emigración (Martínez, 2005: 45). En Jumilla, la mecanización del campo y las nuevas fórmulas empresariales provocaron un exceso de oferta laboral y, con ella, contribuyeron a la depreciación de la mano de obra y a la expulsión de la fuerza laboral del mercado local. 
Tal circunstancia resulta de gran interés científico, ya que reviste las características esenciales que configuran un sistema productivo local. El momento coincide con el despertar de una conciencia propia de territorio, cuando cosecheros y bodegueros dejan de ser sujetos pasivos en el mercado y asumen las riendas de sus destinos. Morales lo describe así: ...las autoridades jumillanas, especialmente aquellas personas ilustradas, comprendieron que la solución estaba en asegurar la venta de sus vinos, para lo cual era necesario perfeccionar las técnicas de elaboración y conseguir las calidades obtenidas por los franceses cuando dirigían ellos estas bodegas, al tiempo que se habrían de mejorar las condiciones del cultivo (1976: 63). Es decir, desarrollar la tercera fase en el esquema de Hinnewinkel, hurtada por la dependencia foránea.

Otros investigadores ya han estudiado los ajustes productivos de la producción de vid y vino a partir del enfoque de sistema productivo local (Alonso, Aparicio, Sánchez, 2004). Más adelante, se emplearán aquí para entender los cambios experimentados en el complejo vitivinícola de base local de Jumilla. Conviene ahora mantener el proceso evolutivo para entender que, sobre la base de esa primera conjunción de intereses entre empresarios, agentes sociales y trabajadores, se fue forjando un concepto de cuenca de trabajo e intereses mutuos, capaz de innovar lo suficiente como para dar respuesta al aumento de la demanda de vino a partir de la segunda mitad del siglo pasado.

Entre las innovaciones tecnológicas registradas a partir de la crisis se hallan las mejoras en las técnicas de cultivo y elaboración de vinos, favorecidas por la inauguración, en 1911, de una Estación Enológica en Jumilla a petición del propio Ayuntamiento. El despertar de una conciencia social y de solidaridad, recogida en la prensa local: Distribuida aqui la riqueza vitícola entre todas las clases sociales y singularmente entre la gran masa de colonos (enfiteutas), habría de ofrecerse un gravisimo problema económico con la pérdida de nuestros actuales viñedos (El Pueblo, 1910). Fruto de ella sería la creación en 1935 del Sindicato Agrícola «El Progreso», germen de la Bodega Cooperativa San Isidro, que permitía a los pequeños cosecheros liberarse del control de comerciantes y especuladores. La sociedad ampliaría sus servicios a los agricultores creando en 1943 una Caja Rural Cooperativa Agrícola. Los empresarios bodegueros comenzaron a embotellar para dar salida a sus productos en forma todavía genérica de vino de mesa (aún quedaba para la diferenciación y la marca). La dinamización de la cuenca de trabajo se consolidaría en 1966 como sistema productivo local al ponerse en marcha, con todas sus implicaciones, el Consejo Regulador de la Denominación de Origen Jumilla, incluyendo bajo esa marca diferenciadora un total de siete municipios de las dos provincias colindantes (Murcia y Albacete).

Contribuía sustancialmente a esa idea de modernización el hecho de que, en el conjunto del País, dentro de los planes de desarrollo y conforme con las 
estrategias de integración progresiva en el mercado Común europeo, se reconociera la singularidad de la vitivinicultura y su importancia para el progreso de algunas zonas concretas, aprobándose, en 1970, el Estatuto de la Viña, del Vino $y$ de los Alcoholes (BOE, 1970).

El Estatuto tenía por objetivo expreso la sistematización y el perfeccionamiento de las prácticas de elaboración del vino: ...teniendo en cuenta el avance de la técnica enológica, los usos en otros países vitivinícolas y las exigencias del mejoramiento de nuestros productos. Además, expresamente, se regulan las tolerancias en los productos, se definen los adulterados y se declara cuáles de los productos no son aptos para el consumo directo, determinando el destino que ha de dárseles. Precisamente para evitar fraudes y la permisibilidad, «teniendo en cuenta los convenios internacionales», se creaba el Instituto Nacional de Denominación de Origen, adscrito al Ministerio de Agricultura, en el que debían integrarse todos los Consejos Reguladores, hasta ese momento con absoluta autonomía y sin más control que el de sus socios (parte interesada).

En la postguerra más que de un proceso de democratización del consumo de vino (cuarta etapa de Hinnewinkel), cabría hablar de un consumo básico determinado por la falta alternativas, con un aporte calórico difícilmente sustituible por otros alimentos, en forma de vino o de destilados (incluso para niños: pan con vino y azúcar). Sin embargo, si puede concretarse como tal el despegue analizado por Morales a partir de 1960. Es el momento en que las grandes bodegas de Jumilla instalan las primeras plantas embotelladoras (antes se embotellaban a mano pequeñas partidas): García Carrión, Juvinsa, Cooperativa San Isidro, Carcelén, Bleda y García Martínez, para sumarse a la iniciativa puesta en marcha por Savin (Sociedad Anónima Vinícola del Norte que también se radicaría en Jumilla), consistente en el desarrollo de un sistema comercial propio, fundamentado en una flota de camiones de la bodega (o vinculada a la bodega) que abastecía los mercados locales de forma periódica con vino embotellado ( $L a$ Semana Vitivinícola, 1988). Hasta esos momentos, la forma habitual de aprovisionamiento era mediante garrafas que el propio consumidor solía rellenar -a granel- en las mismas bodegas productoras, o en algunas tiendas que disponían de barriles que también se rellenaban periódicamente.

La prosperidad económica de los años del desarrollismo (1955-1975) aumentaba la demanda, y el nuevo sistema de embotellado y distribución permitía satisfacer un mercado que se ampliaba y, ahora sí, democratizaba: el vino de mesa embotellado se convertía en alimento habitual de la dieta de las clases medias.

En Jumilla, entre 1955 y 1976 el viñedo pasaba de 16.000 Ha a 30.308 Ha. Morales identifica 1968 como el año en que comienza la escalada de precios, que pasaba de las 3,7 ptas./Kg de 1967 hasta las 10 ptas./kg de 1970. Con todo, la materia prima resultaba insuficiente para abastecer a la gran demanda 


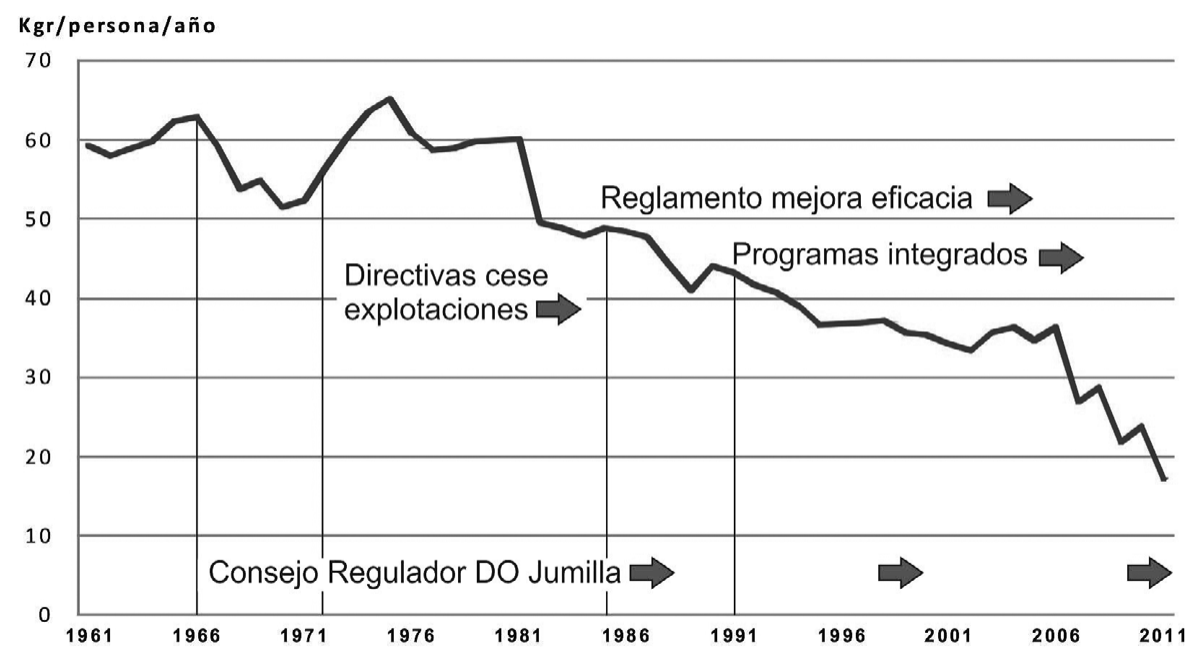

Fig. 1. Evolución del consumo de vino en España, en Kgr/persona/año y momentos significativos: 1966, inauguración Consejo Regulador D.O. Jumilla; 1972, Directivas de cese de explotaciones por incorporación a la U.E.; 1972, Directivas para cese y nueva orientación de las explotaciones; 1985 Reglamentos CEE Mejora Eficacia de las Estructuras Agrarias; 1991, Programas Integrados Mediterráneos. Fuente: FAO (2015), elaboración propia.

bodeguera del momento: en 1974, las bodegas particulares indicaban que se abastecían de $20.984 \mathrm{Ha}$ y la Cooperativa San Isidro de otras $20.512 \mathrm{Ha}$, esto es, de un total de $41.496 \mathrm{Ha}$, cifra muy por encima de la superficie realmente cultivada en el municipio.

\section{La incorporación al Mercado Común Europeo: de la cantidad a la calidad}

Para Hinnewinkel, el factor esencial de éxito radica en la especialización por la búsqueda de la calidad (fase tres), frente a la producción masiva por el aumento de la demanda, siempre afectada por la aparición de nuevos competidores con nueva ventajas comparativas (fase cuatro). A la vista de la evolución reciente de la viticultura en Jumilla, parece que el esquema temporal se ha invertido, y que desde la fase cuatro, el sistema vitivinícola de Jumilla camina hacia la fase tres mediante la contracción y la especialización en nichos de mercado.

La fase expansiva comenzaría a verse afectada, desde principio de los años 1970, por las exigencias derivadas de las estrategias y condiciones de paulatina incorporación al mercado común europeo. Las pretensiones de adhesión de España a la Unión Europea arrancan en 1962, pero la solicitud no tendría respuesta hasta 1970, cuando se firma el primer Acuerdo preferencial con la Comunidad Económica Europea que favorecía las exportaciones agrícolas. No 
obstante la aspiración a ser miembro de pleno derecho exigía ajustar la economía española y, con ella, el sistema agrícola, a las normativa europea.

La temprana incorporación de controles en las explotaciones de vid y en la elaboración de vinos se recoge de forma explícita en el preámbulo del Estatuto de la Viña de 1970: A estos motivos se une el hecho de que las regiones económicas supranacionales, especialmente las europeas, en su marcha hacia una progresiva integración, han llegado ya a adoptar diversos acuerdos relativos a este sector, que pueden afectar al mercado de productos vitivinicolas españoles. Además, la participación de España en instituciones internacionales, como la Oficina Internacional de la Viña y del Vino, constituye una permanente invitación a procurar el mayor acercamiento posible a los criterios que aquéllas recomiendan, tanto en materia de terminología como en lo referente a otras cuestiones técnicas. El Estatuto también incluía ya el principio de ...concesión de auxilios a los viticultores para la transformación de viñas y modernización de los sistemas de explotación, y configurando el régimen de sustitución del viñedo por otros cultivos.

De ese modo, con fundamento legal en el Estatuto de la Viña, antes de la adhesión (Cadenas, Múgica 1983) comenzaban a aplicarse en el campo español las directrices de modernización de las explotaciones: Directiva 72/159 de ayudas para el cese de actividad a los agricultores mayores de 55 años de edad; Directiva 72/160 para la formación de la mano de obra; Directiva 72/161 para el control de la extensión y de las variedades de vid y de las condiciones de su cultivo; Directiva 72/169 para la fijación bajo control de las variedades de la vid en cada D.O. Ese cúmulo de directivas europeas, que afectaban a los países ya miembros, fueron sin duda impulsora de los trabajos de catastro que describe Morales en Jumilla en el momento de redactar su trabajo sobre la vid y el vino (1976: 70), que se plasmarían en el Catastro Vitícola y vinícola de 1975 (publicado en 1978), como objetivo específico del III Plan nacional de Desarrollo (1972-1975).

Con la plena adhesión en 1985 no mejoraría la situación. Diversos autores han señalado que las negociaciones propiciaron un tratamiento muy ventajoso para la actividad industrial en España, pero a costa de fuertes concesiones en el sector primario: pesca y agricultura se verían seriamente afectadas, obligadas a reestructurar y aminorar sus producciones y, además, a esperar diez años para poder beneficiarse del mismo trato que los demás socios comunitarios (Millet, 2003: 525).

En ese periodo, los viñedos de Jumilla se verían afectados por las nuevas disposiciones recogidas en el Reglamento CEE 797/1985 sobre Mejora de la Eficacia de las Estructuras Agrarias, en el 2088/1985 de Programas Integrados Mediterráneos y en el 2328/91 sobre Mejora de las estructuras agrarias (BOE, 1992), que restringía la concesión de ayudas agrarias tan sólo a los agricultores 
que pudiesen demostrar que trabajaban la tierra «a título principal» (tiempo completo), excluyendo directamente a la mitad de los agricultores de Jumilla. Medidas en su conjunto responsables del paulatino abandono del viñedo y de una creciente desafección de los habitantes hacia el medio rural, ante la falta de alternativas viables a la viticultura.

Cuadro 2. Censo Agrario 1999. Explotaciones y dedicación del titular

\begin{tabular}{|c|c|c|c|c|c|}
\hline \multirow{2}{*}{ zona } & \multicolumn{5}{|c|}{ Dedicación del titular } \\
\cline { 2 - 6 } & $\begin{array}{c}\text { explotaciones } \\
\text { con tierra }\end{array}$ & $\begin{array}{c}\text { sólo } \\
\text { explotación }\end{array}$ & $\begin{array}{c}\text { otra actividad } \\
\text { principal }\end{array}$ & $\begin{array}{c}\text { otra } \\
\text { actividad } \\
\text { secundaria }\end{array}$ & $\begin{array}{c}\text { Total } \\
\text { titulares }\end{array}$ \\
\hline $\begin{array}{c}\text { Región } \\
\text { Murcia }\end{array}$ & 59.402 & 33.257 & 22.286 & 2.050 & 57.593 \\
\hline Jumilla & 2.454 & 1.183 & 1.052 & 147 & 2.382 \\
\hline
\end{tabular}

Fuente: INE, Censo Agrario 1999. Elab. prop.

La evolución reciente del viñedo en Jumilla (Figs. 3 y 4) muestra los mismos rasgos de la tendencia general del viñedo en la Región (Fig. 2). No obstante, mientras las cifras que ofrece el Ministerio de Agricultura (2015) parecen matizar el descenso del viñedo, por el contrario, los datos de la Consejería de

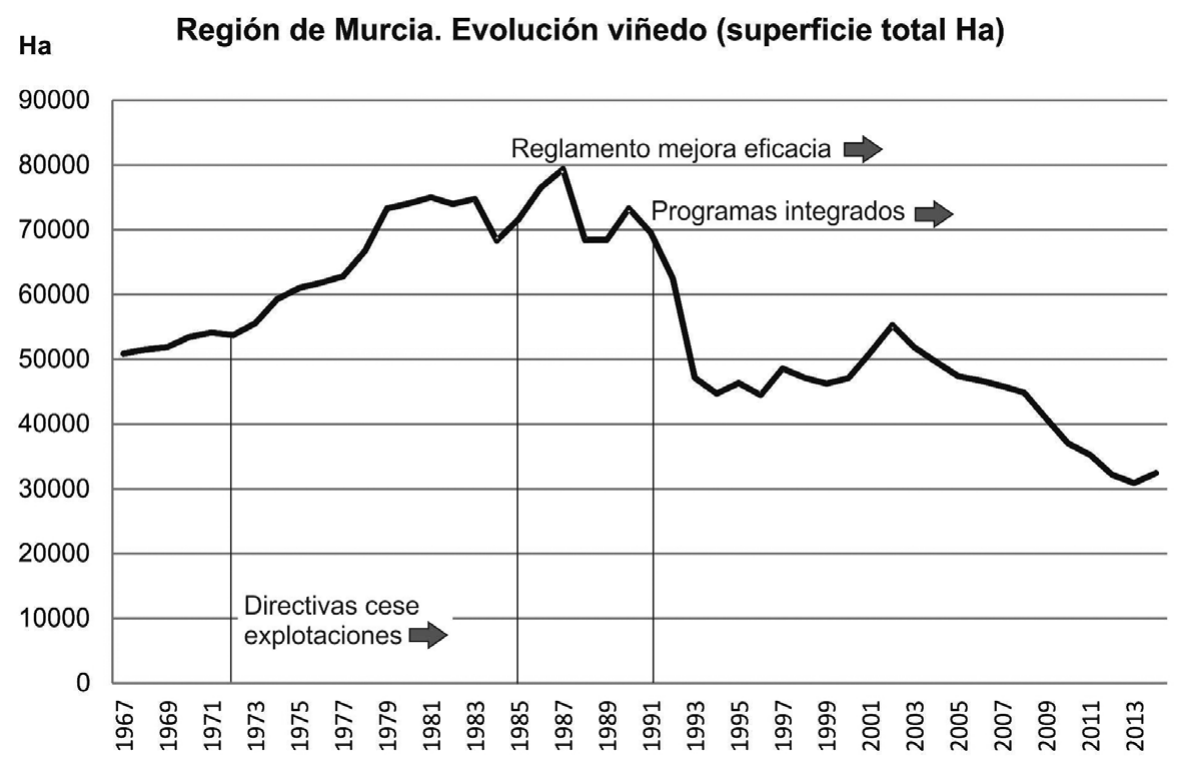

Fig. 2. Evolución reciente de la superficie de viñedo en la Región de Murcia, en Ha. Fuente: INE, Anuarios. Elaboración propia. 


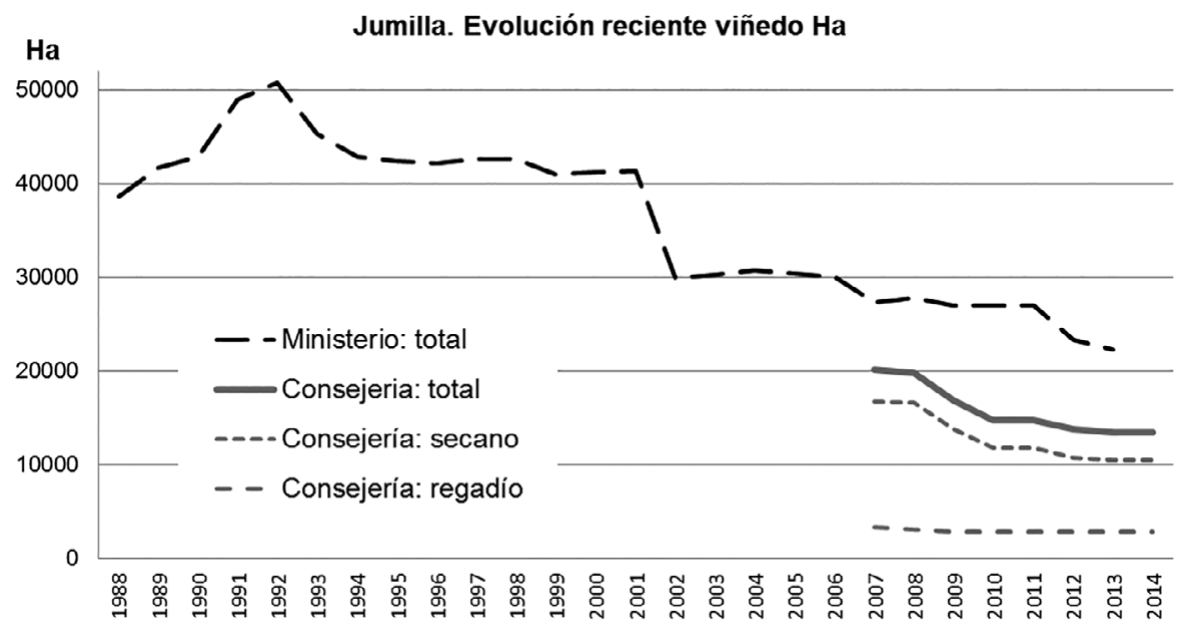

Fig. 3. Evolución reciente del viñedo en Jumilla según el Ministerio de Agricultura y según la Consejería de Agricultura de Murcia (con cifras menores). Fuente: Ministerio Agricultura y Centro Regional Estadísticas Murcia, elaboración propia.
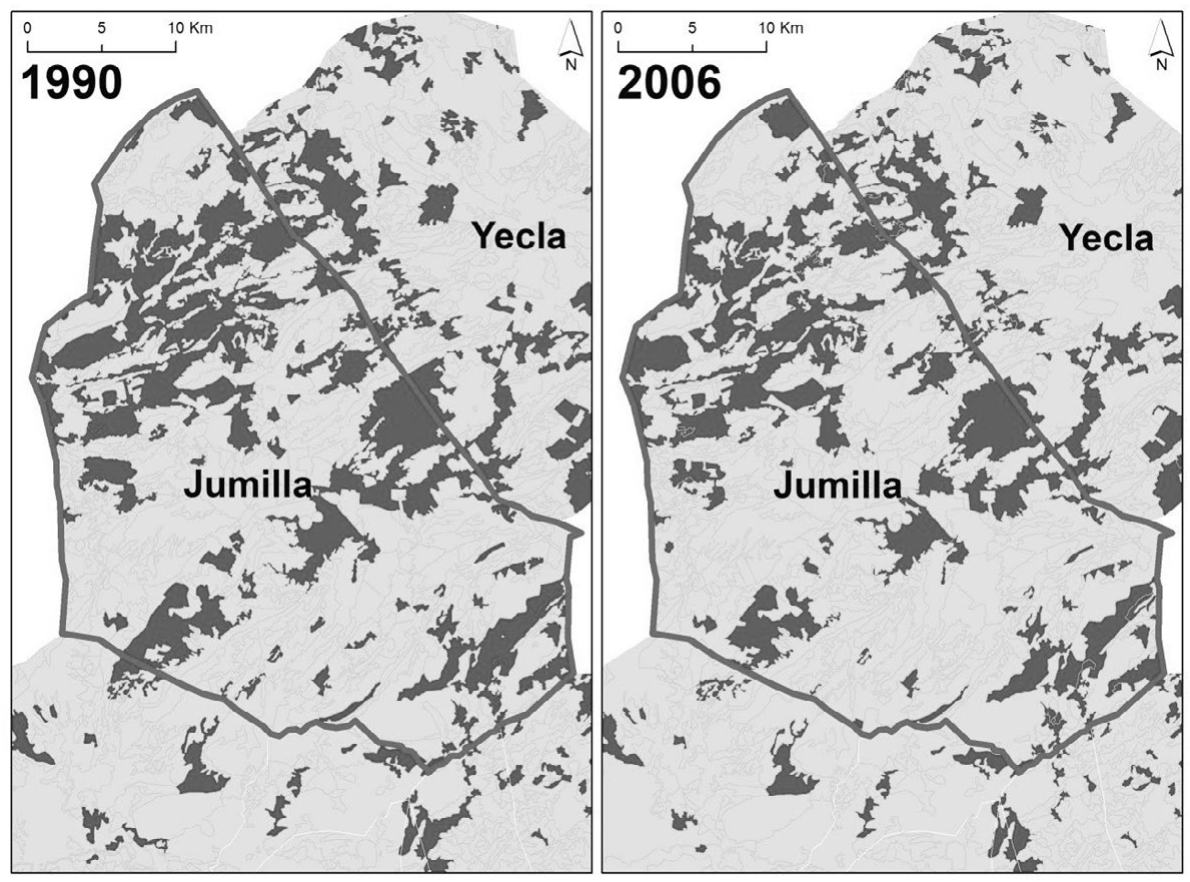

Fig. 4. Evolución reciente de la superficie de viñedo (en negro). Se observa un sensible descenso en la superficie cartografiada, sin embargo, la «superficie inscrita» en las últimas campañas es mucho menor que la cartografiada, que incluye viñedos en diferentes fases de abandono de su cultivo. Fuente: Corine Land Cover 1990 y 2006. 
Agricultura de Murcia (2015) muestran un descenso más acusado, al menos desde 2007.

A la vista de esas cifras, resulta evidente la fuerte especialización viticultora alcanzada por la agricultura de Jumilla. En 1992, el 81\% de la superficie destinada a ese cultivo en la Región se hallaba en Jumilla: 50.808 Ha de un total de 62.516 Ha. Con un crecimiento espectacular desde 1975, en que el Catastro Vitícola registraba $30.308 \mathrm{Ha}$, haciendo buenas las predicciones de Morales (1976: 66): un vasto monocultivo fuertemente especializado en el segmento de vino de mesa, muy competitivo en precios (entre otros motivos por la incorporación desde 1980 del envase no retornable de tetrabrik), convertido en sistema productivo local, competitivo e innovador, actualmente en fase de ajuste y reestructuración, como indicarían las cifras actuales de superficie de viñedo: 22.279 Ha en 2013 según el Ministerio, 13.517 Ha en ese año según la Consejería, y 13.497 Ha en 2014 (Consejería, 2015).

\section{LAS CARACTERÍSTICAS DEL SISTEMA PRODUCTIVO LOCAL DEL VINO}

El complejo vitivinícola desarrollado en Jumilla trasciende los límites municipales y se expande, como cuenca de trabajo y conocimiento, por los demás municipios de la Denominación de Origen Jumilla (Hellín, Tobarra, Albatana, Ontur, Fuente Álamo y Montealegre del Castillo, todos de la provincia de Albacete). Pero también por las D.O. vecinas como Yecla (de la que tan sólo la separan cuestiones administrativas) y Bullas, ambas en la Región de Murcia. Con todo, para este estudio se han centrado los análisis en la configuración del sistema productivo local desarrollado en el municipio de Jumilla. En la figura 5, se ha procedido a estructurar el sistema vitivinícola en tres grandes niveles: productivo, organizativo y normativo (Sánchez, Aparicio y Alonso, 2003).

Ya ha sido analizado el nivel «normativo» y sus efectos sobre el complejo vitivinícola. Se trata de un segmento productivo muy regulado por la Unión Europea, cuyas terminales en Jumilla son el Consejo Regulador de la Denominación de Origen y las instituciones de la administración regional de Murcia. Pero también influyen otros organismos sectoriales, como la Organización Internacional de la vid y el Vino o la Conferencia Española de Consejos Reguladores vitivinícolas. La norma más reciente, la Ley 24/2003 de la viña y del vino (BOE, 2003) insiste en la configuración de sistemas productivos locales al imponer que los vinos de calidad producidos en una región determinada (v.c.p.r.d.) deben ser elaborados con variedades viníferas concretas, recogidas, elaboradas y embotelladas en la misma D.O. o en una circunscripción geográfica reconocida como Asociación de Vino de la Tierra. En el Cuadro 3 se observa como la práctica totalidad del viñedo existente en el municipio de Jumilla se registra para vino de calidad, con normas más exigentes, pero de acuerdo con el objetivo de mejorar el mercado por la vía de la cualificación del producto. 
Cuadro 3. D.O. Región de Murcia, 2013. Superficie de viñedo inscrita para v.c.p.r.d.

\begin{tabular}{|c|c|c|c|c|c|}
\hline \multicolumn{2}{|c|}{ Jumilla } & \multicolumn{2}{c|}{ Yecla } & \multicolumn{2}{c|}{ Bullas } \\
\hline viticultores & superficie & viticultores & superficie & viticultores & superficie \\
\hline 1993 & 22.279 & 493 & 5.824 & 496 & 1.036 \\
\hline
\end{tabular}

Fuente: Ministerio Agricultura. Elab. prop.

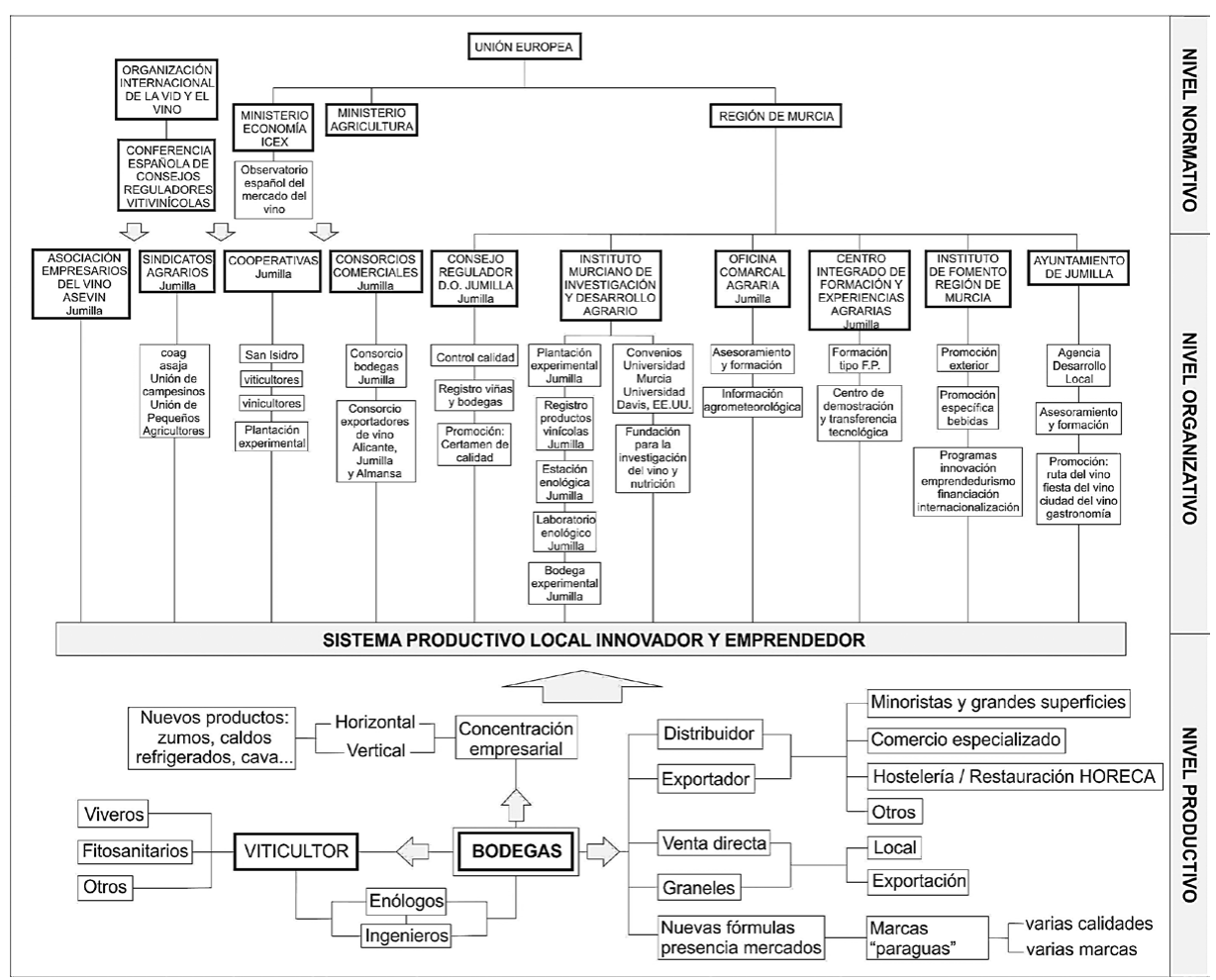

Fig. 5. Elementos y las redes del sistema productivo del vino en Jumilla. Las bodegas aparecen como el Elemento fundamental, el más dinámico e innovador. Elab. prop.

\section{La organización socioinstitucional}

Superada la dependencia del mercado francés de vinos, al menos desde mediados del siglo pasado se ha ido entretejiendo en Jumilla y comarca una tupida red de intereses comunes entorno a la vitivinicultura. La acumulación de experiencia y el descubrimiento de un nicho de mercado específico, fundamentado en el vino de mesa, se hallan en la base de la paulatina configuración de una cuenca local de conocimiento en la que se yuxtaponen redes informales, debidas a la cooperación y buenas relaciones entre los agentes locales, con redes institucionales auspiciadas, en primera instancia, por las bodegas, pero también por las autoridades 
locales y regionales, en la que todos aportan en las tareas de evolución e innovación del negocio común -el vino-, conforme con las especificidades de cada institución o entidad, y con su grado de implicación en el complejo vitivinícola.

En la figura 5 se ha esbozado la maraña de relaciones convocadas en el sistema productivo local de Jumilla. En esa red, destaca sobremanera la importancia de las bodegas como motor del proceso de innovación. La necesaria atención a los gustos cambiantes del mercado es responsable de los constantes procesos de innovación en la elaboración de vinos. Como en épocas anteriores, el mercado manda, pero ahora no son los intermediarios quienes definen las directrices del cambio, sino las propias bodegas autóctonas, merced a una mayor implicación de las mismas en el mercado. En los laboratorios y salas de ensayo de esas bodegas se comprueban las varietales y mezclas que mas se ajustan a los gustos de un mercado internacionalizado, abierto y muy competitivo. Enólogos, químicos e ingenieros agrícolas en plantilla de esas bodegas ensayan, en plantaciones experimentales, la adaptación de nuevas variedades a los suelos y clima de Jumilla, para, finalmente, orientar a los viticultores hacia el cultivo de las varietales de mayores rendimientos y, también, para la adopción de nuevas técnicas de cultivo, cada vez más programadas de manera integral desde la bodega, conforme a sus necesidades y de acuerdo con el calendario de sus tareas.

Es también en las bodegas donde se comprueban las posibilidades de crianza y coupage con el propósito de conseguir las mezclas de vino más ajustadas a las demandas el mercado. Los departamentos comerciales de las bodegas son ahora los encargados de dar salida a la mayor parte de los vinos elaborados, sobre todo a las grandes partidas embotelladas, tipo que en la actualidad supone alrededor del $90 \%$ del total de la producción, cuando a principios de siglo XXI rondaba el $50 \%$ o $60 \%$, y en 1987 tan sólo el $9 \%$ de los vinos exportados se embotellaban (el $81 \%$ se expedía a granel).

Cuadro 4. D.O. Jumilla. Evolución reciente producción y comercialización

\begin{tabular}{|c|c|c|c|c|}
\hline campañas & Total vino HI & \multicolumn{3}{|c|}{ Vino embotellado HI } \\
\hline & & España & Exportación & Total HI \\
\hline $2005 / 06$ & 181.204 & 70.496 & 52.241 & 122.737 \\
\hline $2006 / 07$ & 147.304 & 58.974 & 48.082 & 107.056 \\
\hline $2007 / 08$ & 153.301 & 69.596 & 45.961 & 115.557 \\
\hline $2008 / 09$ & 153.243 & 70.356 & 47.440 & 117.796 \\
\hline $2009 / 10$ & 157.120 & 76.160 & 54.673 & 130.833 \\
\hline $2010 / 11$ & 161.744 & 78.340 & 62.700 & 141.040 \\
\hline $2011 / 12$ & 179.583 & 87.046 & 70.810 & 157.856 \\
\hline $2012 / 13$ & 184.645 & 85.472 & 80.249 & 165.721 \\
\hline
\end{tabular}

Fuente: Instituto Fomento Región de Murcia. 2015, elab. prop. 
A esas tareas de innovación contribuyen decisivamente el Instituto Murciano de Investigación y Desarrollo Agrario, que cuenta en Jumilla con una plantación experimental, una bodega experimental, una estación enológica, un laboratorio enológico y un registro de productos vinícolas. Complementa sus tareas de investigación mediante convenios con diversas universidades, entre ellas la de Murcia y la de Davis en California, especializada en temas de agricultura (de gran prestigio internacional), y a través de la Fundación para la Investigación del Vino y Nutrición, organización de carácter estatal en la que participan diversas universidades del Mundo (en especial las áreas de biomedicina y nutrición). Por lo que respecta a la capacitación de la mano de obra, en la ciudad se halla un Centro Integrado de Formación y Experiencias Agrarias que oferta formación en diferentes niveles, entre ellos el de Formación Profesional, y cuenta con un Centro de Demostración y Transferencia Tecnológica. También contribuyen la Oficina Comarcal Agraria, el Consejo Regulador de la Denominación de Origen y la Agencia de Desarrollo Local del propio Ayuntamiento de Jumilla.

Además de las instituciones, también las organizaciones sociales, empresariales y sindicales se hallan inmiscuidas en los procesos de innovación. La Bodega Cooperativa San Isidro, fundada en 1934 como Sindicato Agrícola, entre otros, tiene el mérito de haber mantenido la tradición vitivinícola y de haber tejido las primeras redes de intereses mutuos en Jumilla. En 1943 creaba una Caja Rural como entidad que permitía la financiación de las labores agrícolas sobre todo de pequeños viticultores, pero también de los medianos y grandes. Los sindicatos agrarios -COAG, ASAJA, Unión de Campesinos y Unión de Pequeños Agricultores- no sólo instruyen y asesoran a los viticultores en tareas de capacitación y cuestiones administrativas y legales, sino que también defienden sus intereses tanto en lo referente a la búsqueda de ayudas, como en las difíciles tareas de negociar cada campaña el precio de la uva, ante la presión a la baja ejercida de manera constante por las bodegas. Por su parte, los empresarios se hallan también organizados en la escala municipal, a través de la Asociación de Empresarios del Vino de Jumilla (ASEVIN) y constituyen el grueso del organigrama del Consejo Regulador de la D.O. En definitiva, una tupida red de relaciones proactivas (y también reactivas o de carácter ordinario), que gravita sobre un mismo interés - la vitivinicultura- en la escala local (principalmente), que permite el funcionamiento del sistema.

\section{La organización de la producción}

La evolución registrada en la cuenca de trabajo de Jumilla es resultado de la respuesta dada por el sistema productivo local a los desafíos de la integración en el hiper-regulado mercado de la Unión Europea, por un lado, y a los crecientes retos planteados por una competencia de carácter global. En ese escenario, la búsqueda de la competitividad y de la optimización de recursos, mano de obra 
y capitales resulta esencial. En ese proceso, se ha pasado de manera paulatina desde una aglomeración de empresas vitivinícolas con escasas relaciones entre sí (condicionadas por las relaciones con los intermediarios y comerciantes foráneos), hasta un clúster o concentración de empresas interconectadas entre sí y con las ventajas comparativas desarrolladas en el territorio (prácticas de gobernanza).

En ese contexto se han desarrollado cadenas de valor específicas, por la proximidad física -clúster geográfico-, por la coincidencia en el negocio-clúster sectorial-con empresas que cooperan en el negocio del vino, por empresas que comparten los mismos recursos (materia prima, capital humano, información, investigación, innovación) en igualdad de condiciones merced al apoyo institucional, cooperativo y asociacionista - clúster horizontal-, e incluso con ejemplos de integraciones verticales de la producción (cosecha, vinificación, comercialización) que apuntan hacia el concepto de clúster verticales (Catalán y otros, 2011).

Del análisis de los procesos, se puede concluir que la nueva organización de la producción se ha dado de forma espontánea, por acumulación de conocimiento, en la medida en que evolucionaban los mercados y los sistemas de transportes han acercado el Altiplano de Jumilla-Yecla (Morales, 1973) a los principales nodos exportadores. A la vez que las empresas mejoraban sus formas de organización (integraciones vertical y horizontal, aprovechamiento de las ventajas comparativas ofertadas por el territorio), de producción (incorporando tecnología e innovación) y de comercialización (sustituyendo la dependencia por la presencia activa en los mercados) (Vázquez, 2006).

Algunos autores han señalado que los sistemas productivos locales tienden a desaparecer a medida que se generalizan los factores en que se basa su competitividad (vino de calidad media -vinos de mesa- a precios competitivos), mientras otras zonas productivas ocupan su posición en el mercado. Sin embargo, Vázquez Barquero (Vázquez, Sáez, 1997) ha puesto de manifiesto que tal situación es reversible si media una adaptación del sistema productivo local a los cambios desafiantes del entorno. En ese proceso, crucial resulta el apoyo alcanzado en las estructuras territoriales (organización social e institucional). Se abunda así en las hipótesis de la crisis creativa argumentada Shumpetter (1963), según la cual, el conglomerado de empresas vitivinícolas de Jumilla habría evolucionado mejorando la calidad del vino, introduciendo nuevos métodos de producción y asumiendo la comercialización, abriendo nuevos mercados (segmentos de calidad y, en especial, hacia la exportación). 
Unas estructuras de propiedad mantenidas en la viticultura

El primer dato objetivo viene dado por el descenso significativo del número de explotaciones, que en Jumilla ha pasado desde las 1.946 de 1974 (Catastro, 1975) a las 894 de 2009 (Censo, 2009): aproximadamente la mitad de las explotaciones de uva para vinificación han desaparecido en el proceso, afectando en igual medida a la superficie ocupada por la viña que, en ese periodo ha pasado desde las 30.308 Ha hasta las 14.099 Ha. También el tamaño de las explotaciones ha experimentado algunas variantes (Fig. 6). Analizados los datos generales de la Región de Murcia (no se dispone de datos locales, pero dado que el viñedo en Jumilla supone más del $80 \%$ del total de la Región de Murcia, parecen muy significativas para el estudio de caso), el tamaño más representativo ha pasado desde las explotaciones comprendidas entre $2 \mathrm{Ha}$ y $5 \mathrm{Ha}$ a las que suman entre $5 \mathrm{Ha}$ y $10 \mathrm{Ha}$, conforme con una lógica de concentración de las explotaciones para hacerlas más viables.

Prácticamente no ha cambiado el régimen de tenencia, Morales señalaba que, en 1974, la mayor parte de los viticultores eran dueños de sus tierras, en gran medida enfiteutas, que las trabajaban como complemento económico de su dedicación principal (Morales, 1976: 76). En 2009, en Jumilla la explotación directa de las tierras seguía siendo la modalidad principal, con 1.074 explotaciones. Muy por detrás quedaban las 174 explotaciones arrendadas y las 63 que perviven en régimen de aparcería. Por lo que respecta a la titularidad jurídica, un total de 849 explotaciones están registradas a nombre del cultivador, tan sólo 21 explotaciones a nombre de una sociedad mercantil y otras 7 explotaciones a nombre de sociedades cooperativas (Censo, 2009).

\section{Region Murcia. Tamaño explotaciones comparado en \%}

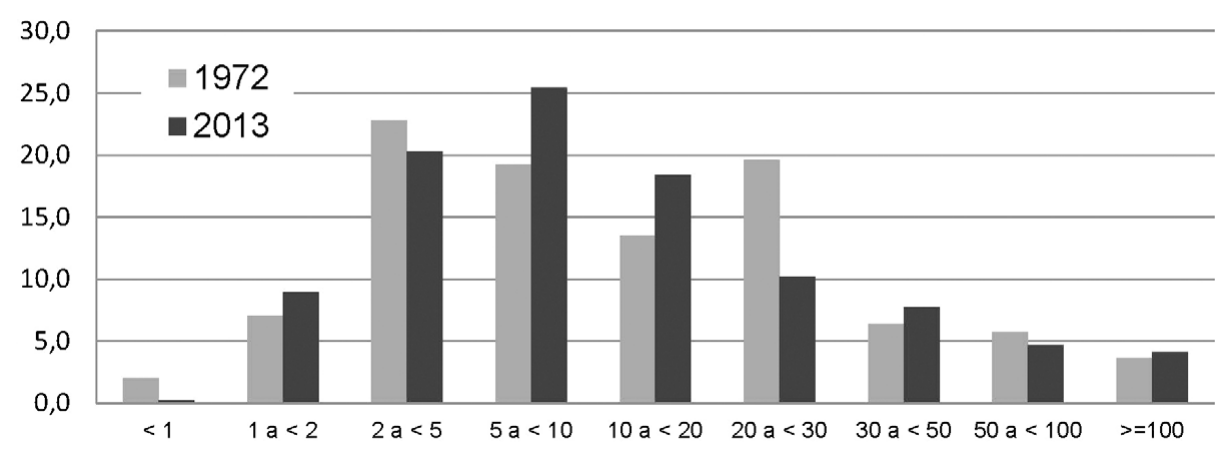

Fig. 6. Región de Murcia. Tamaño comparado en porcentajes de las explotaciones según el Censo Agrario de 1972 y la Encuesta de Estructuras de las Explotaciones Agrícolas de 2013. Elaboración propia. 
Hacia nuevas formas de cultivo tecnificadas

La elaboración de vinos de calidad comienza en los campos, mediante nuevas técnicas de cultivo que garantizan la calidad de la materia prima. Así, el descenso de la superficie se ha dado, sobre todo, por el abandono de los suelos menos aptos (poco profundos y en pendiente), y se ha ido acantonando en los suelos más profundos, de tipo pardo-calizos y calizos, con mediana permeabilidad, que permiten retener la escasa humedad. Sobre todo sobre suelos llanos para facilitar la recolección mecanizada y la incorporación de técnicas de regadío. Del análisis del perfil de los suelos y de sus características físico-químicas se puede determinar el tipo de varietales más ajustadas, o proceder a tratamientos del suelo para corregir deficiencias y potenciar sus virtudes: para la preparación del suelo, a veces se estercola, otras veces se añade fósforo y potasio, que complementan la abundante presencia de calcio. Los viñedos más tecnificados realizan también desinfecciones con nematicidas para evitar la fatiga del suelo.

Por lo común se utilizan plantas porta-injertos certificadas, cuando en 1975 imperaba el pie franco (no afectada por la filoxera, sobre todo en la monastrell), con una gama de varietales muy reducida. El Catastro de 1975 recogía la monastrell como la variedad más extendida en Jumilla, con 27.121 Ha de un total de $30.308 \mathrm{Ha}$. Muy por detrás quedaban otras varietales de gran tradición, como la airén, con $1.060 \mathrm{Ha}$, la moravia con $477 \mathrm{Ha}$, la forcallat blanca (mancheca) con $383 \mathrm{Ha}$ o la messeguera con $153 \mathrm{Ha}$, y hasta un total de otras 34 varietales con muy poca superficie. Mientras la monastrell ha permanecido como seña de identidad de los vinos de Jumilla (si bien pasando desde un $90 \%$ hasta un $80 \%$ del total), las demás varietales tradicionales han desaparecido prácticamente en su totalidad (salvo la airén), sustituidas por un selecto grupo conforme con los nuevos patrones de los gustos de los consumidores, que prefieren tintos de sabores suaves, baja graduación y afrutados, pero con una importante gama de aptitudes enológicas. De ese modo, se han introducido uvas tintas de cencibel, garnacha tintorera, garnacha, cabernet sauvignon, merlot, syrah y petit verdot, y uvas para vinos blancos de varietales como macabeo, Pedro Ximénez, malvasia, chardonnay, sauvignon blanc, moscatel de grano menudo y verdejo. Todas de características reconocidas internacionalmente, con el objetivo de mejorar las mezclas y ajustar la producción a los gustos de los mercados internacionales.

Los suelos llanos permiten la plantación mecanizada, a veces con máquinas plantadoras semiautomáticas, asistidas por láser o GPS. También la incorporación del regadío, mediante sistemas de goteo que permiten añadir nutrientes al suelo -fertirrigación-. Cada vez más, en los viñedos destinados a vinos de calidad, el control del riego se ha convertido en toda una técnica de cultivo, mediante estaciones meteorológicas que determinan el aporte hídrico preciso en cada momento. No obstante, el laboreo tradicional sigue aplicándose al 65\% de 
las tierras, las técnicas del «laboreo mínimo» al 27\%, mientras el resto se halla sin mantenimiento (según declaración) o bajo otras fórmulas más específicas de cultivo como la cubierta vegetal (M.A., 2012), conforme con una tendencia emergente hacia la protección integrada de la vid según criterios medioambientales.

El marco de plantación se ha estrechado y la tendencia apunta hacia densidades de 2.500 a 3.500 cepas por Ha. Pero cada vez son más frecuentes las plantaciones en espaldera (el 17\% en 2012), que facilitan la recolección mecanizada y algunas tareas específicas como la prepoda, el despampanado o el aclareo de racimos.

Si antes la vendimia comenzaba de manera casi inalterable alrededor del 15 de septiembre, ahora se presta mayor atención al grado de maduración de la uva para establecer la fecha de la vendimia, e incluso se atiende a las características de cada varietal, para recolectarlas en el momento óptimo, de acuerdo con las calidades esperadas. Aunque se tiende hacia las vendimiadoras mecanizadas, la oferta de mano de obra coyuntural (inmigrados de temporada) es todavía muy importante en Jumilla, a precios bajos.

La formación específica de la mano de obra y de los empresarios, a través del Centro Integrado de Formación y Experiencias Agrarias de Jumilla, así como la cada vez mayor incorporación de enólogos e ingenieros (agrícolas y químicos) se deja notar en el incremento de la tecnificación de los cultivos y en la potencial mejora de los rendimientos, afectados, no obstante, por la tendencia a la baja de los precios de la uva. Es circunstancia que pasa de coyuntural a tendencial, como se observa en el cuadro 5, denunciada por los sindicatos agrícola que ven en los bodegueros privados a los principales responsables ${ }^{2}$, que estarían pagando precios muy por debajo de los costes de producción, estimado en unos 0,50 euros/kg según la COAG en 2015, campaña por la que se ha pagado un precio medio (según todas las variedades y graduación) de 0,28 euros $/ \mathrm{kg}$ (C.R.D.O. Jumilla información directa).

Cuadro 5. Jumilla. Evolución reciente de los precios de venta de la uva (euros $/ \mathrm{kg}$ )

\begin{tabular}{|l|c|c|c|c|}
\hline \multirow{2}{*}{ variedad } & \multicolumn{4}{|c|}{ Campañas } \\
\cline { 2 - 5 } & $\mathbf{1 9 9 5 - 1 9 9 6}$ & $\mathbf{2 0 0 0}$ & $\mathbf{2 0 0 8}$ & $\mathbf{2 0 1 5}$ \\
\hline Monastrell & 0,41 a 0,44 & 0,30 a 0,38 & 0,21 a 0,24 & 0,21 \\
\hline
\end{tabular}

Fuente: La Semana Vitivinícola, núm. 2565 (1995), 2616 (1996), 2826 (2000), 3240 (2008) y

3457 (2015). Elab. prop.

2. COAG calificaba la actitud de los bodegueros como «ruin y antimurciana, ya que no apuestan por la calidad y ponen en riesgo la buena imagen de los vinos de las Denominaciones de Origen de la Región». www.eldiario.es/.../viticultores-murcianos-reivindican-precios-Jumilla_0... 
Si bien los rendimientos quedan fijados por el Consejo Regulador de la D.O. de Jumilla en $4.000 \mathrm{~kg} / \mathrm{ha}$ para las varietales tintas y $4.500 \mathrm{~kg} / \mathrm{ha}$ para las blancas, y hasta $7.000 \mathrm{~kg} / \mathrm{ha}$ en cultivos intensivos mediante regadío, la realidad es bien distinta, ya que los rendimientos declarados en la campaña de 2006 para el conjunto de la Región de Murcia fueron de $1.536 \mathrm{~kg} / \mathrm{Ha}$ de media en secano y de $4.251 \mathrm{~kg} / \mathrm{ha}$ en regadío, cuando las medias del viñedo español en ese año fueron de $5.274 \mathrm{~kg} / \mathrm{ha}$ y de $10.025 \mathrm{~kg} / \mathrm{ha}$ respectivamente para uva de transformación (M.A., 2006).

Las bodegas y la búsqueda de la calidad como objetivo de competitividad

El gran aumento de la elaboración de vinos en Jumilla que analiza Morales Gil tiene origen en el incremento de la demanda, desde mediados del s. Xx, de vinos de bajo precio y elevada graduación alcohólica, que propiciaron la especialización en vinos de escaso valor añadido. Por el contrario, desde finales de esa centuria, el cambio de patrón operado en el consumo, con el aumento de la renta per capita, se caracterizó por un descenso del consumo y, al tiempo, un aumento de la calidad del vino consumido: en ese periodo se pasó desde un consumo medio de 50 litros/año en 1955, a 69 litros/año en 1975, para descender hasta 46 litros/año en 1990 (Castillo-Compés, 2014: 82).

La exportación se abrió paulatinamente como medida para paliar la caída del mercado interior: en la campaña 1987-1988, sólo el 24\% de la producción de la D.O. Jumilla se dedicaba a la exportación, el 35\% en la campaña 1994-1995 y prácticamente la mitad, el 48,5\%, en la campaña 2012-2013. No obstante, la primera apertura a los mercados internacionales se dio también bajo la fórmula de vinos baratos, sustitutivos de los franceses, muy lastrados en esos mercados por las exigentes regulaciones de la D.O., con grandes dificultades para competir con los vinos más reconocidos de Francia e Italia. Las nuevas estrategias apuntaron hacia la exportación de los vinos de mayor calidad, siempre embotellados, pero regulados en sus mezclas por la exigente D.O., que hallaron también una feroz competencia internacional en los vinos de los nuevos países productores: vinos de mezclas muy ajustadas a las cambiantes modas del mercado, sin regulaciones en sus países de origen, con producciones muy superiores y precios más bajos y competitivos (Fernández-Pinilla, 2014).

En ese sentido, factor limitativo ha sido también la fragmentación empresarial y el pequeño tamaño de las bodegas. En 1956, en Jumilla se registraban 175 bodegas, 54 en 1975 y 29 en 2015 (Consejo Regulador D.O. 2015). Pero la 
reducción del número de empresas no se ha debido a un proceso de concentración empresarial, sino, sobre todo, al importante descenso de la rentabilidad del viñedo y de su cultivo.

De acuerdo con el registro de empresas del Instituto de Fomento de la Región de Murcia (INFO, 2015), en el municipio de Jumilla aparecían domiciliadas 36 bodegas, 21 de ellas integradas en la D.O. y un total de 9 bodegas sin datos ni de actividad, ni de volumen de negocio o empleados. Conforme con la definición la Comisión Europea (Recomendación C/2003/422), las 27 bodegas que aportan datos de empleados y volumen de negocio pueden clasificarse en la forma que sigue:

- 20 microempresa, con menos de diez trabajadores (la moda se sitúa entre 5 y 9 trabajadores) y un volumen de facturación anual inferior a dos millones de euros (la moda se sitúa entre 0,6 y 1,2 millones de $€ /$ año)

- 4 pequeñas empresas, con menos de 49 trabajadores (la moda es de 20 a 49) y un volumen de facturación o total de activo inferior a diez millones de euros (la moda es de 3 a 6 millones de $€ /$ año)

- 2 medianas empresas, con menos de 250 trabajadores (la moda es de 20 a 49 empleados) y un volumen de facturación inferior a cincuenta millones de euros (la moda se sitúa entre 6 y 12 millones de $€ /$ año)

- 1 gran empresa, que sobrepasa esos parámetros: García Carrión, con más de 500 empleados y un volumen de negocio de más de 120 millones de $€ /$ año

Según la actividad declarada, un total de 25 bodegas indican que se dedican por igual a la producción y comercialización de vinos. Todas señalan que una parte de esa comercialización se destina a la exportación, bien que en diferente medida y sin que en ello importe el volumen de negocio de la empresa: por ejemplo, el volumen de exportación de García Carrión ronda el 30\% de su facturación anual, proporción que llega al 100\% en algunas empresas con menos de 300.000

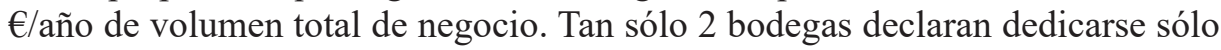
a la comercialización (sin producción) y a la exportación. 
Cuadro 6. Jumilla, 2015. Bodegas según volumen de negocio y empleados

\begin{tabular}{|c|c|c|c|c|}
\hline \multirow[b]{2}{*}{ bodega } & \multirow[b]{2}{*}{ actividad* } & \multirow[b]{2}{*}{ empleados } & \multicolumn{2}{|c|}{ negocio anual (millones $€$ ) } \\
\hline & & & total & exportación \\
\hline García Carrión & $\mathrm{fce}$ & $>500$ & $>120$ & 18 a 36 \\
\hline Luzón & fcep & 20 a 49 & 6 a 12 & 6 a 18 \\
\hline BSI (Cooperativa) & c e p & 20 a 49 & 6 a 12 & 3 a 4,5 \\
\hline Solana del Mayorazgo & $\mathrm{fcp}$ & 10 a 19 & 4,5 a 6 & 4,5 a 6 \\
\hline Casa Ermita & $\mathrm{fce}$ & 20 a 49 & 3 a 6 & 0,6 a 1,2 \\
\hline Olivares & $\mathrm{fce}$ & 5 a 9 & 3 a 6 & 4,5 a 6 \\
\hline Jumillanas de Exportación & $\mathrm{f}$ & 1 a 4 & 3 a 6 & \\
\hline Arloren & fep & 5 a 9 & 1,8 a 3 & \\
\hline Bleda & e p & & 1,8 a 3 & 1,2 a 3 \\
\hline Fernández & fep & 5 a 9 & 1,8 a 3 & 0,3 a 0,6 \\
\hline Juan Gil & $\mathrm{pce}$ & 20 a 49 & 1,8 a 3 & 1,2 a 3 \\
\hline Carchelo & $\mathrm{p} \mathrm{e}$ & 5 a 9 & 0,6 a 1,2 & 0,3 a 0,6 \\
\hline Casa Castillo & $\mathrm{fce}$ & 10 a 19 & 0,6 a 1,2 & 0,3 a 0,6 \\
\hline El Nido & c e p & $1 \mathrm{a} 4$ & 0,6 a 1,2 & 0,6 a 1,2 \\
\hline Hacienda del Carche & $\mathrm{fce}$ & 5 a 9 & 0,6 a 1,2 & \\
\hline Alceño & $\mathrm{fce}$ & 5 a 9 & 0,6 a 1,2 & 0,06 a 0,15 \\
\hline Salzillo & $\mathrm{c} \mathrm{p}$ & 5 a 9 & 0,6 a 1,2 & \\
\hline Silvanogarcía & $\mathrm{fce}$ & 5 a 9 & 0,6 a 1,2 & 0,15 a 0,3 \\
\hline Asensio Carcelén & ec p & 5 a 9 & 0,3 a 0,6 & 0,03 a 0,06 \\
\hline Delampa & $\mathrm{f}$ & $1 \mathrm{a} 4$ & 0,3 a 0,6 & \\
\hline Huerta & e p & 5 a 9 & 0,6 a 1,2 & 0,03 a 0,06 \\
\hline S.A.T. 1832 & c e p & $1 \mathrm{a} 4$ & 0,06 a 0,3 & \\
\hline Casa de las Especias & e p & $1 \mathrm{a} 4$ & 0,06 a 0,3 & $<0,03$ \\
\hline Ego & $\mathrm{c} \mathrm{e}$ & $1 \mathrm{a} 4$ & 0,06 a 0,3 & 0,15 a 0,3 \\
\hline Baldenebro & $\mathrm{fec}$ & & 0,15 a 0,3 & 0,15 a 0,3 \\
\hline Viña Campanero & $\mathrm{fce}$ & $1 \mathrm{a} 4$ & $<0,06$ & \\
\hline Felix Cañadas Jiménez & $\mathrm{c} \mathrm{e}$ & $1 \mathrm{a} 4$ & $<0,06$ & \\
\hline Casa Rojo Enología & $\mathrm{c} \mathrm{e}$ & 10 a 19 & & \\
\hline Viñedo Pico de Garay & c & & & \\
\hline
\end{tabular}

* f: fabricante; c: comerciante; e: exportador; p: productor

Fuente: INFO Región de Murcia, 2015. Elaboración propia 
De acuerdo con las entrevistas realizadas y a partir de las declaraciones de las propias empresas bodegueras, puede concluirse que la integración vertical de viticultores y vinicultores no se ha dado en su conjunto, pero se ha avanzado mucho en ese sentido. Las bodegas organizan así su producción:

- Bodegas con viñedos propios, que elaboran y crían sus propios vinos, y los embotellan. Son las menos, muy orientadas a vinos de alta calidad, que precisan controlar todo el proceso desde la propia viña hasta la comercialización.

- Bodegas con viñedos propios, pero que compran otra uva para elaborar y criar sus vinos. Son la mayoría, que compran uva seleccionada según variedades y calidades para completar su producción.

- Bodegas sin viñedos (o con muy poca extensión), que compran uva para elaborar vinos que venden embotellado o a granel. Son muy pocas.

- Bodegas cooperativas que tratan la uva de sus socios para elaborar y criar vinos, que venden embotellado y, en mayor medida que las anteriores, también a granel. La Bodega San Isidro (cooperativa vitivinícola), es una mediana empresa, que elabora vinos de diferentes calidades y precios y vende a granel.

Desde las bodegas se controla los viñedos propios y los ajenos que suministran uva. Técnicos de las bodegas supervisan la evolución de la vid a lo largo de todo su ciclo vegetativo, participando en las decisiones propias del cultivo. Incluso la propia plantación de las vides queda sujeta a los criterios de las bodegas más preocupadas por la calidad y la trazabilidad de la uva y del vino. De ese modo, se analizan y seleccionan los mejores suelos, los microclimas y altitudes más apropiadas a las características de la variedad de uva, para garantizar la plenitud de las cualidades del vino (color, sabor, aromas, densidades). El propio marco de plantación se adecúa a las necesidades de maduración del fruto, ayudado de tareas específicas como la despampanadura y el aclarado de los racimos para favorecer las calidades de la uva. Tratamientos constantes del suelo controlan las plagas, mientras los riegos localizados programados desde las bodegas conforme con las cambiantes exigencias del tiempo atmosférico, contribuyen a regular el estrés hídrico en busca del óptimo de azúcares para cada vino.

En las plantaciones propias se impone la vendimia mecanizada, que evita la rotura de los racimos y la maceración del mosto antes de tiempo. La tecnificación de las labores en la bodega comienza con un esmerado despalillado para evitar la transmisión de sabores no deseados, y sigue con un absoluto control del proceso de fermentación y maceración mediante frío. Equipadas con laboratorios propios y auxiliadas por los de la Estación Enológica de Jumilla, el personal técnico de las bodegas puede disponer de todos los controles analíticos de calidad y seguridad alimenticia. Son empresas con certificados IFS (International Food 
Standard), BRC (Estándar Mundial del Consorcio Británico de Minoristas para la Seguridad de los Alimentos), ISO 9001 e ISO 14001 (sistema de gestión de la calidad regulado por la International Standard Organization), y desarrollan estrategias de Control de Calidad en Origen para garantizar a los clientes el cumplimiento de las especificaciones de calidad y seguridad alimentaria.

Algunas bodegas, muy centradas en la calidad, disponen de sistemas automáticos de captura de datos en cada fase, que permite definir la trazabilidad absoluta de todos los vinos, desde las viñas hasta su expedición a los clientes: «trazabilidad completa de la cepa a la mesa» (Consejo Regulador, 2015).

La última fase de la integración consiste en la dotación de equipos comerciales propios, o en el diseño de estrategias de comercialización dirigidas o participadas por las bodegas, a veces de manera individualizada y otras bajo diferentes tipos de asociación, que han permitido liberar en parte el sistema productivo del vino en Jumilla de la extrema dependencia de intermediarios foráneos, lanzar marcas propias sustentadas en el aprovechamiento estratégico de todos los activos de la empresa y del territorio (sistema productivo local del vino), mejorando la imagen de la D.O. Jumilla y de sus vinos (de vino de mesa en cantidad a selectos vinos de calidad). Se potencia el valor de la marca, como elemento de diferenciación para la nueva inserción en los mercados nacional e internacional, agrupando la oferta en una selecta y reducida gama de vinos, para ganar dimensión, capacidad y poder de negociación.

Ahora bien, la marca vinculada directamente con el mercado constituye un camino de doble dirección: el mercado impone gustos y precios, que llegan a través de la marca (y sus estrategias de comercialización) a las bodegas, y éstas repercuten sobre sus propios viñedos y técnicas de cultivo y elaboración de vinos. Pero también sobre los demás agricultores que suministran la materia prima -la uva-beneficiados por la incorporación constante de conocimiento en sus cultivos, pero sujetos a la dictadura de precios determinada en los mercados. Las bodegas, bien capitalizadas, pueden adaptar su producción a las fluctuaciones de la demanda, mediante estrategias de flexibilidad que repercute, sobre todo, en los pequeños viticultores que suministran la uva complementaria, que ven año tras año mermada la rentabilidad de sus plantaciones. Puede decirse que, mientras se da un evidente retorno de la cadena de valor hacia las bodegas (en forma de conocimiento y beneficios económicos), los agricultores de base ven cercenado ese retorno de valor. Y ello pese a que algunas de esas bodegas tienen el certificado RSC (Responsabilidad Social Corporativa), sistema de gestión que promueve prácticas laborales que aportan beneficios a toda la cadena de suministro. 


\section{CONCLUSIONES}

Del análisis de la evolución reciente de complejo vitivinícola desarrollado en Jumilla después de 1976, momento en que Morales Gil cerraba su trabajo, puede afirmarse que la apertura a los mercados ha ocasionado una profunda transformación, afectada también por las regulaciones derivadas de la integración plena en la Unión Europea. El tránsito desde una cuenca productora de vino de mesa de alta graduación a precios bajos, que impulsó el cultivo de la vid por la mayor parte de las tierras fértiles del municipio, hasta un sistema productivo local innovador e integrado se ha saldado con una drástica reducción de la superficie de cultivo, el desarrollo de estrategias de calidad y competitividad en todas las fases (cultivo, cosecha, elaboración y comercialización), y en el desarrollo de una organización territorial donde se entretejen las redes de cooperación y colaboración entre agricultores, empresas e instituciones.

Sobre nuevas estructuras empresariales mejor organizadas y competitivas, se observa un proceso de concentración vertical que vela por la calidad en cada fase, con el propósito de garantizar la trazabilidad del producto ajustado, no sólo a los gustos del mercado, sino también a las normas más exigentes de calidad alimentaria. La capacidad de intervenir de manera directa en la comercialización ha obligado a las antiguas empresas, de marcado carácter familiar, a poner en práctica exitosas estrategias de branding para crear nuevas marcas (a veces para potenciar las existentes), que hiciesen posible superar la negativa imagen arrastrada: primero vinos de baja calidad para el mercado nacional (en la etapa que analiza Morales Gil) y luego vinos de imitación de los franceses a bajos precios en los mercados internacionales.

Puede concluirse que la cuenca de conocimiento de Jumilla ha evolucionado hacia un territorio inteligente, entendido como aquél capaz de construir sus propias ventajas competitivas, sobre la base de las ventajas comparativas que ofrece el medio, en estrecha relación con su entorno (medio físico y social y contexto institucional), haciendo posible un desarrollo económico en armonía con el desarrollo social (Vegara-De las Rivas, 2004). No obstante, encontramos un sensible déficit en el sistema local, ya que la competitividad económica y empresarial alcanzada por las bodegas, pese a lograr avances también en la cohesión social del municipio, no termina de redundar en los pequeños viticultores en la medida que sería deseable, conforme con su rango de piedra angular de todo el sistema. 


\section{BIBLIOGRAFÍA CITADA}

Alonso, J.L., Aparicio, J., SÁnchez, J.L. (2002): «Procesos de innovación en los sistemas productivos locales de castilla y León», en Revista de Economía y Finanzas de Castilla y León, 5, pp. 77-116

Alonso, J.L., Aparicio, J., SÁnchez, J.L. (2004): «Redes y procesos de innovación en la industria vinícola de Castilla y León: hacia la formación de un entorno innovador», en Recursos territoriales y Geografía de la innovación industrial en España. Salamanca. Ed. Aquilafuente, pp. 106-134

Boletín Oficial del Estado (1970): Ley 25/1970, de 2 de diciembre, de Estatuto de la Viña, del Vino y de los Alcoholes. BOE núm. 291, de 5 de diciembre de 1970, páginas 19816 a 19829. En línea http://www.boe.es/diario_boe/txt.php?id=BOEA-1970-1316 [14/8/2015]

Boletín Oficial del Estado (1992): Real Decreto 1887/1991, de 30 de diciembre, sobre mejora de las estructuras agrarias. BOE. núm. 2, de 2 de enero de 1992, páginas 74 a 84. En línea http://www.boe.es/diario_boe/txt.php?id=BOE-A-1992-127 [14/8/2015]

Boletín Oficial del Estado (2003): Ley de la viña y del vino. BOE núm. 165 de 11 de Julio de 2003. En línea http://www.boe.es/diario_boe/txt.php?id=BOEA-2003-13864 [14/8/2015]

Cadenas, A.; MúgicA, J.M. (1983): Economía de la viticultura española: análisis comparado con la vitivinicultura de la CEE, INIA, Madrid, 100 pp.

CASTILlo, J.S., Compés, R. (coord.) (2014): La economía del vino en España y en el Mundo. Cajamar Caja Rural. 737 pp.

Catalan, J., Miranda, J.A. Ramon-Muñoz, R., eds. (2011): Distritos y Clusters en la Europa del Sur. Madrid. LID, 490 pp.

Cebrián Abellán, A., Cano Valero, J. (1992): Relaciones topográficas de los pueblos del reino de Murcia. Universidad de Murcia.

Consejería de Agricultura Murcia (2015): «Evolución de la superficie según municipios y tipo de cultivo. Secano y regadío». Centro Regional de estadísticas de Murcia. En línea http://www.carm.es/econet/sicrem/PU590/sec19_c23.html [22/10/2015]

Consejo Regulador D.O. Jumilla (2015): Vinos de Jumilla. En línea http://www. vinosdejumilla.org [18/09/2015]

Diario Oficial de La Comunidad Europea (1972, 1973): Directivas. En línea http:// www.boe.es/doue/1973/356/L00085-00086.pdf [14/09/2015]

Deloitte (2007): Plan estratégico de la Denominación de Origen de vinos de Jumilla. En línea http://www.vinosdejumilla.org/files/plan_estrategico_completo_

010307.pdf [16/09/2015]

Dirección General de Agricultura (1891): Avance estadístico sobre cultivo y producción de la vid en España. Madrid. 256 pp.

El Pueblo (1910), El Pueblo (semanario de Jumilla), 25/09/1910

FAO (2015): «Faostat». Food and Agriculture Organization of the United Nations. Statistics Division. En línea: http://faostat3.fao.org/home/E [25/10/2015] 
Fernández, E., Pinilla, V. (2014): «Historia económica del vino en España (18502000)». En La economía del vino en España y en el Mundo. Cajamar Caja Rural. pp. $67-98$

Girón LARRUCEA, J.A. (2002): La Unión Europea. La Comunidad Europea y el Derecho comunitario. Sevilla. Universidad de Sevilla. 658 pp.

Gil OlcinA, A. (1979): La propiedad señorial en tierras valencianas, Valencia, Del Cenia al Segura, $276 \mathrm{pp}$.

Herrero Castro, J.L. (1987): «Las condiciones de vida y consumo en la España de la postguerra: determinación del ingreso y poder de compra de una familia tipo». En Estudios sobre consumo, n. ${ }^{\circ}$ 10, abril. En línea http://consumo-inc.gob.es/publicac/ EC/1987/EC10/ec10_01.pdf [18/10/2015]

HinNEWINKEL, J-C. (2007), «L'avenir du terroir : gérer de la complexité par la gouvernance locale», Méditerranée, 109, pp. 17-22

InE (varios años), Anuario Estadístico de España. En línea http://www.ine.es/prodyser/ pubweb/anuarios_mnu.htm [22/10/2015]

INFO (2015): Documentación y publicaciones. Región de Murcia. En línea https://www. institutofomentomurcia.es/web/exterior/estadisticas [9/11/2015]

La Semana Vitivinícola (1988): «Savin», La Semana vitivinícola, Volumen 43, Números 2178-2185

Martínez CARrión, J.M. (2005): «En busca del bienestar: las migraciones en la Historia de la Región de Murcia». Campus digital. Universidad de Murcia. Pp. 33-60. En línea https://www.um.es/campusdigital/Libros/textoCompleto/condicioninmigrante. htm [4/9/2015]

Millet, M. (2003): «Negociación e impacto económico de una ampliación: el caso de España». En Lecturas de integración económica: la Unión Europea. Barcelona. Universitat de Barcelona. Pp. 519-538

Ministerio de Agricultura (1978): «Murcia». Catastro vitícola y vinícola. Tomo 30, $106 \mathrm{pp}$.

Ministerio de Agricultura (2012): Encuesta sobre superficies y rendimientos. En línea: http:/www.magrama.gob.es/es/estadistica/temas/estadisticas-agrarias/ VI\% C3\%B1edo2012_tcm7-271019.pdf [12/08/2015]

Ministerio de Agricultura (2015): «Encuesta de viñedo». Estadísticas agrarias. En línea: http:/www.magrama.gob.es/es/estadistica/temas/estadisticas-agrarias/agricultura/encuestas-de-vinedo/ [12/08/2015]

Molina Grande, M. ${ }^{a}$ C.; Molina García, J. (1991): Carta Arqueológica de Jumilla, Real Academia Alfonso X el Sabio, Murcia, 208 pp.

Morales Gil, A. (1970): «La propiedad rural en el Altiplano de Jumilla-Yecla durante los siglos XVIII y XIX», en Papeles del Departamento de Geografía, n. ${ }^{\circ} 2$, pp. 109-129

Morales GiL, A. (1973): «Las comunicaciones en Murcia ante el desarrollo económico regional». En Papeles del Departamento de Geografía, Universidad de Murcia, pp. $119-156$

Morales Gil, A. (1976): La vid y el vino en la zona de Jumilla. Academia Alfonso X el Sabio. Murcia. 149 pp. 
Muns Albuixech, J. ed. (2003): Lecturas de integración económica: la Unión Europea. Barcelona. Universitat de Barcelona. $611 \mathrm{pp}$.

Oestreicher, A. (2005): «La filoxera en España. Bases para su estudio y consecuencias socio-económicas en la Región de Murcia», R. M. Antropología, 12, U.M., pp. 199-208

Palencia Pérez, R. (1963): «Los rasgos característicos del viñedo jumillano», en Anales de la Universidad de Murcia, vol. XXI, pp. 154-188

Pedreño, A., Hernández, M. (2005): La condición de inmigrante. Exploraciones e investigaciones dese la región de Murcia. Campus Digital Universidad de Murcia. 378 pp. En línea https:/www.um.es/campusdigital/Libros/textoCompleto/ condicioninmigrante.htm [4/9/2015]

Piqueras HabA, J. (1981): La vid y el vino en el País Valenciano. Alfons el Magnànim. Valencia. 346 pp.

Piqueras Haba, J. (2000): El legado de Baco. Los vinos valencianos: desde la antigüedad hasta nuestros días. Gules. Valencia. $430 \mathrm{pp}$.

Plasencia, P. (1994): Los vinos de España vistos por los viajeros europeos. Madrid, Ministerio Agricultura, $168 \mathrm{pp}$.

Ponce Herrero, G. (2003): Reestructuración y territorio en los sistemas productivos industriales valencianos. Universidad de Alicante. Alicante. 383 pp.

Ponce Herrero, G. (2014): «El viñedo alicantino como terroir en crisis». Libro jubilar en homenaje al profesor Antonio Gil Olcina. Universidad de Alicante. Pp. 513-532

PovedA, R. (2008) «Algunas referencias de extranjeros y coterráneos al vino de Alicante», Canelobre, n. ${ }^{\circ}$ 54, Dip. Alicante, Alicante, pp. 83-92

Sánchez, J.L., Aparicio, J., Alonso, J.L. (2003): «Densidad institucional, gestión del conocimiento y procesos de innovación en la industria vinícola de Castilla y León». Ería, n. ${ }^{\circ}$ 61. Pp. 177-195

SÁnchez, J.L., Aparicio, J., Alonso, J.L. (2004): «Redes y procesos de innovación en la industria vinícola de Castilla y León: hacia la formación de un entorno innovador». En Recursos territoriales y Geografía de la innovación industrial en España. Salamanca. Universidad de Salamanca. Pp. 106-134

Shumpetter, J.A. (1963): Teoría del desenvolvimiento económico. México. Fondo de Cultura Económica. 255 pp.

Unwin, T. (2001): El vino y la viña. Geografía histórica de la viticultura y del comercio del vino. Tusquet. Barcelona, $536 \mathrm{pp}$.

VÁzQUEZ BARQUERO, A. (2006): «Surgimiento y transformación de cluster y milieus en los procesos de desarrollo». En Revista Eure. Santiago de Chile. Vol. XXXII, n. ${ }^{\circ} 95$, pp. 75-92. En línea http://www.scielo.cl/pdf/eure/v32n95/art05.pdf [28/09/2015]

Vázquez Barquero, A., Sáez Cala, A. (1997): «La transformación de los sistemas productivos locales y la globalización del entorno económico. La respuesta de los distritos valencianos del calzado a los desafíos de la competitividad». En Revista Valenciana d'Estudis Autonómics, n. ${ }^{\circ}$ 19, pp. 37-58

Vegara, A., De las Rivas, J.L. (2004): Territorios Inteligentes. Madrid. Fundación Metrópoli. 323 pp. En línea http://issuu.com/fundacionmetropoli/ docs/territorios inteligentes_fundacion_metropoli [12/11/2015] 